УДК 591.5:594.1

doi: $10.25128 / 2078-2357.20 .1-2.11$

${ }^{1}$ А. П. СТАДНИЧЕНКО, ${ }^{1}$ Г. Е. КИРИЧУК, ${ }^{2}$ Е. И. УВАЕВА, ${ }^{1}$ Д. А. ВИСКУШЕНКО

${ }^{1}$ Житомирский государственный университет имени Ивана Франко

ул. Большая Бердичевская, 40, Житомир, 10002

${ }^{2}$ Государственный университет «Житомирская политехника»

ул. Чудновская, 103, Житомир, 10005

e-mail: bio-2016@ukr.net

\title{
ВЛИЯНИЕ ВЫСОКИХ КОНЦЕНТРАЦИЙ ДЕТЕРГЕНТА «SARMA» НА АКТИВНОСТЬ IN VITRO РЕСПИРАТОРНОГО МЕРЦАТЕЛЬНОГО ЭПИТЕЛИЯ SINANODONTA WOODIANA (LEA, 1834)
}

Исследовали влияние анионактивного детергента «Sarma» в высоких концентрациях на продолжительность работы и частоту биения in vitro ресничек мерцательного эпителия жаберного аппарата самцов, самок и гермафродитных особей беззубки китайской Sinanodonta woodiana (Lea, 1834). Детергент «Sarma» в концентрациях 3 и 6 мг/дм в среде пребывания беззубки удлиняет продолжительность локомоции ресничек и увеличивает частоту их биения. Исследованный детергент в диапазоне концентраций 12-48 мг/дм ${ }^{3}$ способствует сокращению значений обеих показателей в $1,2-6,2$ и в $1,1-8,3$ раз соответственно в сравнении с нормой.

Ключевые слова: беззубка, СМС, респираторный эпителий.

В настоящее время антропогенный прессинг на гидросферу привел к загрязнению природных вод компонентами как промышленных, так и хозяйственно-бытовых стоков $[4,10,18]$. Среди них опасными для гидробионтов являются поверхностно-активные вещества (ПАВ) компоненты синтетических моющих средств (CMC), функцией-мишенью которых у всех жабродышащих животных является мерцательный эпителий их жаберного аппарата. Степень поражения последнего под влиянием поверхностно-активных веществ (ПАВ) обусловливается как концентрацией этого токсиканта, так и физиологическим статусом особей, подвергшихся его воздействию [13, 15-17].

Начало XXI ст. в Украине ознаменовалось появлением и быстрым распространением (сперва в Северном Причерноморье - в Килийской дельте Дуная, несколько позже - в Закарпатье) беззубки китайской Sinanodonta woodiana (Lea, 1834) - вида-иммигранта, проникшего сюда, скорее всего, по дунайскому инвазионному коридору [11, 20-22]. Этот моллюск юго-восточноазиатского происхождения отличается широкой экологической валентностью, чем и обусловлено его успешное быстрое расселение, особенно в последние десятилетия, в пресных континентальных водоемах (как проточных, так и стоячих) разных континентов [14, 23-26]. Успешность существования появившихся в Украине популяций этого вида-вселенца в значительной мере будет зависеть от степени устойчивости его к загрязнению детергентами заселенных им поверхностных вод. Насколько существенной для китайской беззубки является роль этого антропогенного фактора свидетельствует тот факт, что при действующих в настоящее время ПДК, принятых для ПАВ (0,5 мг/дм ${ }^{3}$ - для анионактивных и $0,1 \mathrm{мг/м^{3 }}$ - для неионогенных), содержание их в природных водах к настоящему времени в ряде регионов Украины превышено в десятки и сотни раз [9].

Выяснение этого вопроса важно в том отношении, что у этой беззубки, как и у всех остальных Bivalvia, от уровня активности респираторного эпителия зависят все важнейшие функции ее жизнеобеспечения. На сегодня установлено только влияние ПАВ на частоту сердцебиения у этого моллюска разных условий температурного режима [5].

Цель работы - выяснить особенности влияния на продолжительность работы и частоту биения in vitro ресничек фронтального мерцательного эпителия жаберного аппарата S. woodiana при воздействии на нее детергента «Sarma» в высоких концентрациях. 


\section{Материал и методы исследования}

Материал исследования - 342 особи S. woodiana (длина раковин - 12,9-16,1 см, высота 8,6-9,7 см), собранных вручную в Килийской дельте Дуная у западной границы заповедника «Дунайские плавни» (Одесская обл.) в июне 2011 г. В лабораторию животных транспортировали обернутыми 6-ю слоями мокрой мешковины. В стационарных условиях их сразу же подвергли обязательной предшествующей токсикологическому эксперименту 15суточной акклимации (объем аквариумов - 50-100 л, плотность посадки особей - 1 екз./10 л воды, температура воды $-20-22^{\circ} \mathrm{C}, \mathrm{pH}-7,4-8,6$, оксигенизация - 8,5-9,3 мг $\mathrm{O}_{2} /$ дм $^{3}$ ) [19]. Обновление среды ежесуточное, как и кормление особей (растертый сухой корм для рыб).

Токсикологический эксперимент поставлен по стандартной методике [1]. Как токсикант использован детергент «Sarma» (производитель - «Винницабытхим»), который является одним из наиболее востребованных в последние годы в Украине, включительно в Северном Причерноморье. Состав детергента, заявленный производителем: сульфаты (более 30\%), карбонаты (5-15\%), фосфаты (5-15\%), анионные ПАВ (5-15\%), неионогенные ПАВ $(<5 \%)$, кислородсодержащие отбеливающие вещества (5-15\%), силикаты (5-15\%), пеногаситель (< $5 \%)$, фосфонаты $(<5 \%)$, антисорбенты $(<5 \%)$, поликарбоксилаты $(<5 \%)$, энзимы, оптические отбеливатели, отдушка.

Ориентировочным опытом для $S$. woodiana установлены значения (мг/дм $\left.{ }^{3}\right) \mathrm{LC}_{0}=0,1$ и $\mathrm{LC}_{100}=100$, а графически (методом скользящей кривой) $-\mathrm{LC}_{50}=50$. В основном опыте задействовано CMC в 5-ти концентрациях в пределах $\mathrm{LC}_{0}-\mathrm{LC}_{50}$ (таблица). Экспозиция -2 сут.

Продолжительность активности функционирования и частоту биения ресничек фронтального мерцательного жаберного эпителия определяли на временных микропрепаратах по стандартной методике [3], воспользовавшись микроскопом «Биолам» (×200 и ×450) со сниженной степенью освещенности поля зрения (диафрагмирование осветителя). Пол моллюсков устанавливали по [21]. Результаты опыта обработаны методами базовой вариационной статистики [6].

Таблица

Влияние детергента «Sarma» на активность локомоции in vitro ресничек мерцательного эпителия жаберного аппарата Sinanodonta woodiana

\begin{tabular}{|c|c|c|c|c|c|c|}
\hline \multirow[b]{2}{*}{ Материал } & \multicolumn{3}{|c|}{ Продолжительность локомоции (ч) } & \multicolumn{3}{|c|}{ Частота биения (уд./мин) } \\
\hline & $n$ & lim & $\begin{array}{c}\mathrm{M} \pm \mathbf{m} \\
\mathbf{C V}\end{array}$ & $n$ & lim & $\begin{array}{c}\mathrm{M} \pm \mathrm{m} \\
\mathbf{C V}\end{array}$ \\
\hline \multicolumn{7}{|c|}{ Контроль } \\
\hline Самцы & 11 & $96-297$ & $\begin{array}{c}228,3 \pm 16,2 \\
10,4\end{array}$ & 11 & $223-337$ & $\begin{array}{c}310,4 \pm 5,8 \\
7,9\end{array}$ \\
\hline Самки & 13 & $115-349$ & $\begin{array}{c}235,7 \pm 10,1 \\
8,6\end{array}$ & 12 & $241-360$ & $\begin{array}{c}329,3 \pm 6,9 \\
6,3\end{array}$ \\
\hline Гермафродиты & 10 & $110-318$ & $\begin{array}{c}220,1 \pm 12,3 \\
7,4\end{array}$ & 10 & $230-352$ & $\begin{array}{c}314,1 \pm 4,3 \\
3,8\end{array}$ \\
\hline \multicolumn{7}{|c|}{3 мг/дм ${ }^{3}$} \\
\hline Самцы & 9 & $99-311$ & $\begin{array}{c}243,1 \pm 11,6 \\
12,8\end{array}$ & 10 & $241-338$ & $\begin{array}{c}327,3 \pm 7,8 \\
4,2 \\
\end{array}$ \\
\hline Самки & 12 & $117-326$ & $\begin{array}{c}251,1 \pm 13,3 \\
11,9 \\
\end{array}$ & 11 & $237-349$ & $\begin{array}{c}355,5 \pm 6,9 \\
5,0\end{array}$ \\
\hline Гермафродиты & 8 & $120-319$ & $\begin{array}{c}249,3 \pm 15,9 \\
7,7\end{array}$ & 9 & $225-354$ & $\begin{array}{c}333,2 \pm 9,4 \\
3,9\end{array}$ \\
\hline \multicolumn{7}{|c|}{$6 \mathrm{Mг} / \mathrm{дм}^{3}$} \\
\hline Самцы & 12 & $119-347$ & $\begin{array}{c}295,7 \pm 16,8 \\
9,9\end{array}$ & 12 & $248-411$ & $\begin{array}{c}400,2 \pm 8,6 \\
5,4\end{array}$ \\
\hline Самки & 13 & $122-339$ & $\begin{array}{c}319,9 \pm 15,5 \\
11,4\end{array}$ & 12 & $259-443$ & $\begin{array}{c}407,3 \pm 9,8 \\
6,6 \\
\end{array}$ \\
\hline Гермафродиты & 9 & $141-356$ & $\begin{array}{c}323,5 \pm 19,4 \\
10,1\end{array}$ & 8 & $216-339$ & $\begin{array}{c}372,3 \pm 6,7 \\
4,8\end{array}$ \\
\hline
\end{tabular}

78 ISSN 2078-2357. Наук. зап. Терноп. нац. пед. ун-ту. Сер. Біол., 2020, № 1-2 (79) 


\begin{tabular}{|c|c|c|c|c|c|c|}
\hline \multicolumn{7}{|c|}{ Продолжение таблицы } \\
\hline \multicolumn{7}{|c|}{12 мг/дм ${ }^{3}$} \\
\hline Самцы & 11 & $112-323$ & $\begin{array}{c}210,3 \pm 16,3 \\
11,4\end{array}$ & 12 & $231-333$ & $\begin{array}{c}309,8 \pm 8,7 \\
5,6 \\
\end{array}$ \\
\hline Самки & 10 & $107-338$ & $\begin{array}{c}201,9 \pm 19,8 \\
16,5\end{array}$ & 10 & $225-319$ & $\begin{array}{c}297,4 \pm 4,3 \\
6,7\end{array}$ \\
\hline Гермафродиты & 6 & $99-315$ & $\begin{array}{c}209,3 \pm 14,6 \\
12,8\end{array}$ & 8 & $218-339$ & $\begin{array}{c}312,3 \pm 6,7 \\
4,8\end{array}$ \\
\hline \multicolumn{7}{|c|}{24 мг/дм ${ }^{3}$} \\
\hline Самцы & 13 & $74-168$ & $\begin{array}{c}124,3 \pm 10,1 \\
8,7\end{array}$ & 11 & $84-110$ & $\begin{array}{c}103,6 \pm 3,4 \\
4,1\end{array}$ \\
\hline Самки & 13 & $69-153$ & $\begin{array}{c}120,1 \pm 9,5 \\
6,6\end{array}$ & 9 & $79-136$ & $\begin{array}{c}94,8 \pm 6,7 \\
7,7\end{array}$ \\
\hline Гермафродиты & 9 & $85-143$ & $\begin{array}{c}115,8 \pm 10,3 \\
10,1\end{array}$ & 8 & $88-134$ & $\begin{array}{c}100,3 \pm 5,1 \\
5,9\end{array}$ \\
\hline \multicolumn{7}{|c|}{48 мг/дм ${ }^{3}$} \\
\hline Самцы & 10 & $37-59$ & $\begin{array}{c}42,4 \pm 7,3 \\
12,5\end{array}$ & 10 & $31-53$ & $\begin{array}{c}45,1 \pm 3,2 \\
3,7\end{array}$ \\
\hline Самки & 10 & $33-57$ & $\begin{array}{c}38,5 \pm 8,9 \\
12,1\end{array}$ & 11 & $29-51$ & $\begin{array}{c}42,4 \pm 1,6 \\
5,4\end{array}$ \\
\hline Гермафродиты & 7 & $29-44$ & $\begin{array}{c}36,6 \pm 7,4 \\
10,3\end{array}$ & 7 & $22-49$ & $\begin{array}{c}31,5 \pm 2,2 \\
6,1\end{array}$ \\
\hline
\end{tabular}

Примечание: $n$ - количество исследованных моллюсков, экз.; lim - минимальное и максимальное значения; $\mathrm{M} \pm \mathrm{m}$ - среднее значение показателя с погрешностью к среднему; CV - коэффициент вариации, \%.

\section{Результаты исследования и их обсуждение}

При 3 мг/дм ${ }^{3}$ ПАВ в среде у всех подопытных $S$. woodiana отмечена тенденция к возрастанию как длительности активности респираторного эпителия, так и частоты биения его ресничек. При 6 мг/дм ${ }^{3}$ токсиканта подобного рода сдвиги достигают уровня высокой статистической достоверности $(p<0,01)$, составляя у самцов, самок и гермафродитов прирост (в \%) для продолжительности активности $21,8,27,5,16,3 \%$, а для частоты биения - 22,2, 14,3, 11,7 \% соответственно. Дальнейшее повышение концентрации детергента в среде (с 6 до 48 мг/дм³) сопровождается быстро нарастающим сокращением значений обоих обсуждаемых показателей: у самок - в 8,3 и 8,4 раза, у самцов - в 7,0 и 7,3, у гермафродитов - в 8,8 и 10,6 раза соответственно $(p<0,01)$. Наименьшую степень сдвига значений этих показателей выявлено у самцов, а наибольшую - у гермафродитов.

К настоящему времени установлено, что пребывание моллюсков в средах, содержащих ПАВ, в зависимости от их концентрации, продолжительности воздействия и уровня резистентности к ним этих гидробионтов, сопровождается развитием у них патологического процесса - отравления, каждая из стадий которого характеризуется присущим ей симптомокомплексом $[15,17]$. Настоящим исследованием выявлено, что 3 и 6 мг/дм ${ }^{3}$ ПАВ в среде провоцируют развитие у $S$. woodiana отравление в форме стадии стимуляции, свидетельством чего являются как приведенные выше данные о возрастании активности ее респираторного эпителия, так и проявление у отравленных особей быстрой защитной физиологической реакции в виде интенсификации ослизнения фронтального жаберного эпителия, замедляющей диффундирование детергента внутрь особей.

В среде, содержащей 12 мг/дм ${ }^{3}$ токсиканта, у беззубок развивается депрессивная стадия патологического процесса. Симптомы начального ее этапа («ранняя» депрессия) значительное (на 4,34-8,17\%) сокращение продолжительности работы мерцательного эпителия у всех, без исключения, категорий исследованных моллюсков. Частота биения ресничек при этом существенно сокращается только у самок (на $6,86 \%$ ), тогда как у самцов и гермафродитов она составляет лишь 0,19 и $0,70 \%$ соответственно. Наблюдается возрастание ослизнения 
эпителия жабр, появление рассыпанной мелкозернистой пастозности покровных тканей мантии и ноги, указывающее на начало развития оводнения, а значит и отечности последних. Степень повреждаемости особей на этой стадии их отравления, однако, такова, которая обеспечивает $100 \%$-ную их выживаемость вплоть до конца экспозиции (на данном этапе эксперимента).

При 24 мг/дм ${ }^{3}$ ПАВ через 9-12 ч. с начала опыта состояние беззубок соответствует обычному для завершения стадии депрессии («поздняя» депрессия). Для нее характерны патологические изменения респираторного эпителия и кровотечения, быстрое возрастание отечности мягких тканей и ослабления тактильной чувствительности. Тем не менее, к завершению 1-ых суток опыта все особи все еще сохраняли жизнеспособность. Полагают [2, 7 , 8], что это связано с их переходом на анаэробный способ использования основного энергетического субстрата - гликогена. Эта адаптация позволяет беззубкам некоторое время выжить в условиях аноксии. При этом, однако, на неповрежденных участках респираторного эпителия продолжительность его работы сокращается вдвое, а частота биения ресничек втрое. Ко второй половине суток от начала опыта у всех подопытных особей отмечаются выраженные симптомы следующей стадии отравления - сублетальной. Для нее характерны тотальная деструкция респираторного эпителия, обширные разлитые отеки мягкого тела, полное обездвиживание особей, обильное одномоментное опорожнение кишечника. К завершению срока экспозиции у $22,8 \%$ особей отмечено развитие завершающей стадии процесса отравления - летальной (в форме «истинного шока»).

При 48 мг/дм ${ }^{3}$ ПАВ у всех подопытных особей стремительно развивается состояние, соответствующее переходу от «поздней» депрессии в течение $0,5-1,0$ сут. в быстро следующее друг за другом сублетальную и летальную стадии. К завершению срока экспозиции смертность подопытных беззубок составляет 98-100\%.

Характер изменений показателей продолжительности активности и частоты биения ресничек мерцательного эпителия беззубки в зависимости от уровня содержания детергента в среде их пребывания полностью соответствуют концепции Г. Селье [12], согласно которой небольшие напряжения («эустрессы») в противовес перенапряжениям («дистрессам») оптимизируют жизненную активность организмов, повышая их адаптационные возможности в относительно новых условиях существования. В нашем исследовании эустресс проявлялся при детергента в концентрациях 3 и 6 мг/дм ${ }^{3}$, тогда как превышающие их концентрации вызывали дистресс.

Исходя из полученных результатов, поскольку к последней четверти XX ст. уровни содержания в природных водах Украины анионактивных и неионогенных ПАВ превысили значения установленных для них ПДК в 40-200 раз, возможность выживания в них адвентивного вида $S$. woodiana является весьма сомнительной, особенно если учесть, что детергенты очень долго сохраняются в водоемах не разлагаясь.

\section{Выводы}

Продолжительность работы фронтального мерцательного эпителия жаберного аппарата и частота биения его ресничек определяются концентрацией ПАВ в среде обитания беззубки китайской $S$. woodiana. Снижение эффективности работы ее респираторного эпителия происходит при воздействии на этих моллюсков детергентом в концентрации 12 мг/дм³ вызывающей у них морфо-физиологические повреждения, ведущие к снижению уровня их общего метаболизма и сопротивляемости действию токсиканта. Повышение концентрации ПАВ до 24 мг/дм ${ }^{3}$ усиливает чувствительность беззубок к воздействию повреждающего фактора. Интенсивность патоморфологических сдвигов в структурах их организма, ответственных за фильтрацию воды, а следовательно, и за дыхание, резко возрастает. При этом сохранение жизнеспособности особями обеспечивается благодаря наличию у них защитноприспособительных физиологических реакций. Учитывая то, что в настоящее время уровень загрязнения детергентами природных вод Украины местами катастрофически высок, а эти соединения очень долго сохраняются в водной среде, выжить в таких условиях, не взирая на ее очень широкую экологическую валентность, S. woodiana не сможет. 
1. Алексеев В. А. Основные принципы сравнительно-токсикологического эксперимента. Гидробиол. журн. 1981. Т. 71, № 3. С. 92-100.

2. Биргер Т. И., Маляревская А. Я. О некоторых биохимических механизмах резистентности водных беспозвоночных к токсическим веществам. Гидробиол. журн. 1985. Т. 13, № 6. С. 69-73.

3. Веселов Е. А. Биологические тесты при санитарно-биологическом изучении водоемов. Жизнь nресных вод СССР. М.-Л. : Изд-во АН СССР, 1959. Т. 4, Кн. 2. С. 7-37.

4. Єрмошина Т. В. Робота війок миготливого епітелію перлівницевих в умовах антропогенного прессу. Житомир : Житомир. держ. ун-т, 2008. 146 с.

5. Иззатуллаев 3. И., Стадниченко А. П., Янович Л. Н. и др. Комплексное воздействие поверхностноактивных веществ (ПАВ) и температурного режима на сердцебиение Sinanodonta woodiana (Mollusca, Bivalvia, Unionidae). Научн. вестн. Самарканд. гос. ун-та. 2017. С. 157-161.

6. Лакин Г. Ф. Биометрия. М. : Высш. шк., 1980. 293 с.

7. Маляревская А. Я., Карасина Ф. М. Влияние некоторых поверхностно-активных веществ на гидробионтов. Гидробиол. журн. 1983. Т. 19, № 5. С. 84-90.

8. Маляревская А. Я. Биохимические механизмы адаптации гидробионтов к токсическим веществам. Гидробиол. журн. 1985. Т. 21, № 3. С.70-82.

9. Поліщук В. В., Трав'янко В. С., Коненко Т. Д., Тарасевич І. Г. Гідробіологія і гідрохімія річок Правобережного Придніпров’я. К.: Наук. думка, 1978. 208 с.

10. Романенко В. Д. Основи гідроекології. К. : Обереги, 2001. 723 с.

11. Сон М. О. Моллюски-вселенцы в пресных и солоноватых водах Северного Причерноморья. Одесса : Друк, 2007. 132 с.

12. Селье Г. Стресс без дистресса. М. : Прогресс, 1982. 352 с.

13. Стадниченко А. П., Иваненко Л. Д. Влияние различных концентраций поверхностно-активных веществ на содержание сухого остатка гемолимфы роговой катушки. Mater. IX Miedzynarod. nauk.praktyczn. konfer. «Europejska nauka XXI powieka», 2013. Vol. 24. S. 29-35.

14. Стадниченко А. П. Види-вселенці у складі прісноводної малакофауни України: зб. наук. праць «Водні і наземні екосистеми та збереження їх біорізноманіття». Житомир : Б. в., 2019. С. 57-59.

15. Уваєва О. І. Порушення очищувальної роботи Viviparus contectus (Mollusca: Pectinibranchia: Viviparidae) за сумісної дії детергентів та трематодної інвазії. Наук. вісн. Волинського нац. ун-ту ім. Лесі Украӥнки. Біол. науки. 2012. №2 (27). С. 45-49.

16. Уваєва О. І. Вплив безфосфатного детергента на фільтраційну роботу калюжниці болотяної. Екологічні науки. 2018. № 1 (20). Т. 2. С. 86-91.

17. Уваєва О. І., Сарган А. П. Вплив синтетичних миючих засобів на фільтраційну активність прісноводних молюсків. Наук. записки Терноп. наи. пед. ун-ту ім. В. Гнатюка. 2011. № 2 (47). С. 147-150.

18. Филенко О. Ф., Михеева И. В. Основы водной токсикологии. М. : Колос, 2007. 142 с.

19. Хлебович В. В. Акклимация животных организмов. Л. : Наука, 1981. 136 с.

20. Янович Л. Н., Пампура М. М. Новая находка Sinanodonta woodiana (Bivalvia, Unionidae) в бассейне Дуная Украины (морфобиологическая характеристика). Наук. вісн. УжНУ. Серія: біол. 2012. Вип. 32. С. $145-149$.

21. Янович Л. М. Перлівницеві Unionidae Rafinesque, 1820 (Bivalvia) в сучасних екологічних умовах України (стан популяцій, особливості статевої структури і розмноження, біоценотичні зв'язки та фауна): автореф. дис. на здобуття наук. ступеня докт. біол. наук. Київ, 2013. 48 с.

22. Янович Л. Н., Пампура М. М. Новая находка моллюска-вселенца Sinanodonta woodiana Lea, 1834 (Mollusca: Bivalvia: Unionidae) в Украине. Вестн. зоол. 2011. Т. 45, № 2. С. 186.

23. Bogan A. E. A new threat to conservation of north american freshwater mussels Chinese Pond Mussel Sinanodonta woodiana in the United States / A. E. Bogan, J. Bowers-Altman, M. Raley // Tentacle. - 2011. - Vol. 19. - P. 39-40.

24. Djajasasmita M. The occurence of Anodonta woodiana (Lea, 1834) in Indonesia (Pelecypoda: Unionidae) / M. Djajasasmita // Veliger. - 1982. - Vol. 25. - P. 175.

25. Douda K. The role of host specificity in explaining the invasion success of the freshwater mussel Anodonta woodiana in Europe / K. Douda, M. Vrtilek, O. Slavik, M. Reichard // Biological invasion. - 2012. - Vol. 14. - P. 127-137.

26. Piechocki A. Freshwater and Marine Mollusca of Poland / A. Piechocki, B. Wawrzyniak-Wydrowska. Poznań: Bogucki Wydawnictwo naukowe, 2016. - 352 s. 


\section{References}

1. Alekseev V. A. Osnovnye printsipy sravnitelno-toksikologicheskogo eksperimenta / V.A. Alekseev // Gidrobiol. zhurn. - 1981. - T. 71, № 3. - S. 92-100. [in Russian]

2. Birger T. I. O nekotorykh biokhimicheskikh mekhanizmakh rezistentnosti vodnykh bespozvonochnykh $\mathrm{k}$ toksicheskim veshchestvam / T.I. Birger, A.Ya. Malyarevskaya // Gidrobiol. zhurn. - 1985. - T. 13, № 6. S. 69-73. [in Russian]

3. Veselov Ye. A. Biologicheskie testy pri sanitarno-biologicheskom izuchenii vodoemov / Ye.A. Veselov // Zhizn presnykh vod SSSR. - M.-L. : Izd-vo AN SSSR, 1959. - T. 4, Kn. 2. - S. 7-37. [in Russian]

4. Jermoshyna T. V. Robota vijok myghotlyvogho epiteliju perlivnycevykh $\mathrm{v}$ umovakh antropoghennogho pressu / T.V. Jermoshyna. - Zhytomyr: Zhytomyr. derzh. un-t, 2008. - 146 s. [in Ukrainian]

5. Izzatullaev Z. I. Kompleksnoe vozdeystvie poverkhnostno-aktivnykh veshchestv (PAV) i temperaturnogo rezhima na serdtsebienie Sinanodonta woodiana (Mollusca, Bivalvia, Unionidae) / Z.I. Izzatullaev, A.P. Stadnichenko, L.N. Yanovich i dr. // Nauchn. vestn. Samarkand. gos. un-ta. - 2017. - S. 157-161. [in Russian]

6. Lakin G. F. Biometriya / G.F. Lakin. - M.: Vyssh. shk., 1980. - 293 s. [in Russian]

7. Malyarevskaya A. Ya. Vliyanie nekotorykh poverkhnostno-aktivnykh veshchestv na gidrobiontov / A.Ya. Malyarevskaya, F.M. Karasina // Gidrobiol. zhurn. - 1983. - T. 19, № 5. - S. 84-90. [in Russian]

8. Malyarevskaya A. Ya. Biokhimicheskie mekhanizmy adaptatsii gidrobiontov k toksicheskim veshchestvam / A.Ya. Malyarevskaya // Gidrobiol. zhurn. - 1985. - T. 21, № 3. - S.70-82. [in Russian]

9. Polishhuk V. V. Ghidrobiologhija i ghidrokhimija richok Pravoberezhnogho Prydniprov'ja / V.V. Polishhuk, V.S. Trav'janko, T.D. Konenko, I.Gh. Tarasevych. - K. : Nauk. dumka, 1978. - 208 s. [in Ukrainian]

10. Romanenko V. D. Osnovy ghidroekologhiji / V.D. Romanenko. - K. : Obereghy, 2001. - 723 s. [in Ukrainian]

11. Son M. O. Mollyuski-vselentsy v presnykh i solonovatykh vodakh Severnogo Prichernomorya / M.O. Son. - Odessa : Druk, 2007. - 132 s. [in Russian]

12. Sele G. Stress bez distressa / G. Sele. - M. : Progress, 1982. - 352 s. [in Russian]

13. Stadnichenko A. P. Vliyanie razlichnykh kontsentratsiy poverkhnostno-aktivnykh veshchestv na soderzhanie sukhogo ostatka gemolimfy rogovoy katushki / A.P. Stadnichenko, L.D. Ivanenko // Mater. IX Miedzynarod. nauk.-praktyczn. konfer. «Europejska nauka XXI powieka». 2013. - Vol. 24. - S. 29-35. [in Russian]

14. Stadnychenko A. P. Vydy-vselenci u skladi prisnovodnoji malakofauny Ukrajiny // Zb. nauk. pracj «Vodni i nazemni ekosystemy ta zberezhennja jikh bioriznomanittja»/ A.P. Stadnychenko. - Zhytomyr : B. v., 2019. - S. 57-59. [in Ukrainian]

15. Uvajeva O. I. Porushennja ochyshhuvaljnoji roboty Viviparus contectus (Mollusca: Pectinibranchia: Viviparidae) za sumisnoji diji deterghentiv ta trematodnoji invaziji / O.I. Uvajeva // Nauk. visn. Volynsjkogho nac. un-tu im. Lesi Ukrajinky. Biol. nauky. - 2012. - №2 (27). - S. 45-49. [in Ukrainian]

16. Uvajeva O. I. Vplyv bezfosfatnogho deterghenta na filjtracijnu robotu kaljuzhnyci bolotjanoji / O.I. Uvajeva // Ekologhichni nauky. - 2018. - №1 (20). - T. 2. - S. 86-91. [in Ukrainian]

17. Uvajeva O. I. Vplyv syntetychnykh myjuchykh zasobiv na filjtracijnu aktyvnistj prisnovodnykh moljuskiv / O.I. Uvajeva, A.P. Sarghan // Nauk. zapysky Ternop. nac. ped. un-tu im. V. Ghnatjuka. - 2011. - № 2 (47). - S. 147-150. [in Ukrainian]

18. Filenko O. F. Osnovy vodnoy toksikologii / O.F. Filenko, I.V. Mikheeva. - M. : Kolos, 2007. - 142 s. [in Russian]

19. Khlebovich V. V. Akklimatsiya zhivotnykh organizmov / V.V. Khlebovich. - L. : Nauka, 1981. - 136 s. [in Russian]

20. Yanovich L. N. Novaya nakhodka Sinanodonta woodiana (Bivalvia, Unionidae) v basseyne Dunaya Ukrainy (morfobiologicheskaya kharakteristika) / L.N. Yanovich, M.M. Pampura // Nauk. visn. UzhNU. Seriya : biol. - 2012. - Vip. 32. - S. 145-149. [in Russian]

21. Yanovich L. M. Perlivnycevi Unionidae Rafinesque, 1820 (Bivalvia) v suchasnykh ekologhichnykh umovakh Ukrajiny (stan populjacij, osoblyvosti statevoji struktury i rozmnozhennja, biocenotychni zv'jazky ta fauna) / L.N. Janovych. Avtoref. dys. dokt. biol. nauk. - Kyjiv, 2013. - 48 s. [in Ukrainian]

22. Yanovich L. N. Novaya nakhodka mollyuska-vselentsa Sinanodonta woodiana Lea, 1834 (Mollusca: Bivalvia: Unionidae) v Ukraine / L.N. Yanovich, M.M. Pampura // Vestn. zool. - 2011. - T. 45, №2. S. 186. [in Russian] 
23. Bogan A. E. A new threat to conservation of north american freshwater mussels Chinese Pond Mussel Sinanodonta woodiana in the United States / A.E. Bogan, J. Bowers-Altman, M. Raley // Tentacle. - 2011. - Vol. 19. - P. 39-40.

24. Djajasasmita M. The occurence of Anodonta woodiana (Lea, 1834) in Indonesia (Pelecypoda: Unionidae) / M. Djajasasmita // Veliger. - 1982. - Vol. 25. - P. 175.

25. Douda K. The role of host specificity in explaining the invasion success of the freshwater mussel Anodonta woodiana in Europe / K. Douda, M. Vrtilek, O. Slavik, M. Reichard // Biological invasion. - 2012. - Vol. 14. - P. 127-137.

26. Piechocki A. Freshwater and Marine Mollusca of Poland / A. Piechocki, B. Wawrzyniak-Wydrowska. Poznań: Bogucki Wydawnictwo naukowe, 2016. - 352 s.

\author{
${ }^{1}$ A. P. Stadnychenko, ${ }^{1}$ H. Ye. Kyrychuk, ${ }^{2}$ O. I. Uvaieva, ${ }^{1}$ D. A. Vyskushenko \\ ${ }^{1}$ Zhytomyr Ivan Franko State University, Ukraine \\ ${ }^{2}$ Zhytomyr Polytechnic State University, Ukraine
}

\title{
EFFECT OF HIGH CONCENTRATIONS OF «SARMA» DETERGENT ON IN VITRO ACTIVITY OF RESPIRATORY CILIATORY EPITHELIUM OF SINANODONTA WOODIANA (LEA, 1834)
}

Nowadays the anthropogenic pollution of natural water bodies has become significant. In Ukraine, the pollutants, which are highly hazardous for aquatic organisms, include detergents entering water bodies as part of municipal fecal sewage. One of the pollutants is the synthetic detergent «Sarma», which is currently in high demand. This is a multi-component detergent containing 5-15\% anionic and $<5 \%$ nonionic surfactants, that in all gill-breathing animals target the ciliated epithelium of their gill apparatus. The degree of damage is determined by the concentration of this toxicant in the aquatic environment, and the resistance of aquatic organisms to its effects.

The purpose of the study was to determine the effects the frontal ciliated epithelium has on the activity of the frontal ciliary epithelium in the gill apparatus of the Chinese pond mussel Sinanodonta woodiana (Lea, 1834) at high concentrations. Pollution of natural water bodies has now reached the level of $40-200 \mathrm{mg} / \mathrm{dm}^{3}$ in a number of regions of Ukraine. This is despite the fact that the currently valid TLV standards are $0.5 \mathrm{mg} / \mathrm{dm}^{3}$ for anionic surfactants, and $0.1 \mathrm{mg} / \mathrm{dm}^{3}$ for nonionic surfactants in Ukraine. It should be mentioned that the object of our study is an invading mollusk species, which at the beginning of the current century used the Danube River as an invasive corridor to enter the Kiliysky Danube Delta and form thriving populations with high densities. A toxicologic experiment was used to study the effect of 5 concentrations of the «Sarma» detergent $(3,6,12,24$, and 48 $\mathrm{mg} / \mathrm{dm}^{3}$ ) on the duration and frequency of beating of cilia of the frontal epithelium on gills of male, female, and hermaphroditic specimens of $S$. woodiana. Exposition time was 2 days. At $3 \mathrm{mg} / \mathrm{dm}^{3}$ of toxicant in the medium, the values of both discussed parameters had a tendency towards increasing. At $6 \mathrm{mg} / \mathrm{dm}^{3}$ of toxicant, that trend was replaced by shifts of the same direction with a high degree of reliability $(p<0.01)$. Within the concentration range of 12 to $48 \mathrm{mg} / \mathrm{dm}^{3}$, the inhibitory effect of the toxicant is observed to increase for both studied parameters. The above-mentioned changes in the activity of the respiratory epithelium of $S$. woodiana occur against the background of a developing stage-by-stage pathological process of poisoning. At $6 \mathrm{mg} / \mathrm{dm}^{3}$ of the toxicant, the stage of stimulation is observed; at $12 \mathrm{mg} / \mathrm{dm}^{3}$, an «early» depression; at $24 \mathrm{mg} / \mathrm{dm}^{3}$, a "late" depression; at $48 \mathrm{mg} / \mathrm{dm}^{3}$, sublethal and lethal stages. Each of the poisoning stages corresponds to a complex of various symptoms, represented by a set of certain qualitative and quantitative rapid physiological and behavioral reactions, both pathological and protective, due to the toxicant influence. The populations of the invading species $S$. woodiana are not able to survive if the level of surfactant pollution reaches $40 \mathrm{mg} / \mathrm{dm}^{3}$ in the northern Black Sea water system.

Key words: Sinanodonta woodiana, detergents «Sarma», кespiratory epithelium.

Надійшла 15.04.2020. 